\title{
Bulletproof Materials
}

For centuries, people have used tough clothing materials to protect themselves. These materials ranged from layers of fibers to heavy metal plates and tough new materials such as synthetic fiber composites and cermets.

The use of quilted and padded material for protection replaced simple hides at about the same time woven fabrics replaced treated skins for clothes. The ancient Egyptians created light and practical bodily protection by superimposing layers of prepared and woven flax. As early as 600 A.D., the Chinese developed armor of padded silk layers. Europeans copied the technique of quilted armor from the Saracens, who brought it from the East.

About the 14th century, mounted warriors began to wear heavy armor made of steel plates. While this protected nearly every part of a knight's body, the armor was also so heavy that the man could barely move, and so costly that only the wealthy could afford a suit of armor.

Infantrymen needed much lighter protection because they required a high degree of mobility. Footsoldiers, archers, musketeers, and pikemen typically wore quilted jackets reinforced with leather or pieces of metal or bone. In the 15th century, Louis XI passed an ordinance requiring all his footsoldiers to wear linen coats that were 30 layers thick, with an option to cover the top with deerskin.

When conquistadors such as Pizarro and Cortez reached the Americas in the 15th century, they encountered Indians who wore bodily protection made of quilted cotton jackets studded with overlapping hardwood plates. This proved so effective against the conquistadors' weapons that they adopted the armor themselves.

With the increasing use of gunpowder in warfare, armored garments had to protect the wearers from bullets. In Elizabethan times, a protective doublet-called a "jack" - was made from plates of iron sewn between folds of linen; it weighted $21 \frac{1 / 2}{2}$ pounds. Padded, layered armor was also introduced. As described by one English lawyer: "An abundance of silken backplates and breastplates were made and sold that were pretended to be pistol proof in which any man dressed was safe as in a house, for it was impossible that any one could strike at him for laughing, so ridiculous was the figure."

However, in certain circumstances the bulletproof jackets were indeed effective. One Swiss jacket on display in New York's Metropolitan Museum consists of nine layers of linen, weighing only three and onehalf pounds; within the layers is imbedded a lead bullet that did not penetrate completely, but merely forced the inner surface to bulge. Presumably, the wearer survived what would otherwise have been a fatal wound.

The First World War used a large amount of high-explosive artillery shells, which led to a high percentage of wounds from flying shell fragments. Some special-purpose troops were issued experimental torso armor made of steel and fiber layers designed to be impervious to bullets, but this armor proved too heavy for general use.

During World War II, $80 \%$ of all casualties were caused by shell fragments, and $70 \%$ of all wounds affected the torso. Great efforts were made by both the military and industry to develop lightweight, efficient body armor. Ground troops and bomber crews wore experimental vests made of resin-bonded fiberglass, steel, aluminum, and heavy nylon cloth.

Protective vests for aircraft personnel were called "Flak" suits, from the German for "anti-aircraft artillery." These became popular at the end of World War II and were heavily used in the Korean War. Flak vests contained plates of manganese steel or a laminate of glass fabric bonded with a polyester resin, trade named Doron. In the Korean War alone, the use of body armor is credited with reducing casualties by $20 \%$.

Semiflexible vests made of plates and basket-weave nylon were used after 1951 by the U.S. army and navy. Such vests protected against mortar fragments and artillery fragments, but could not stop armor-piercing bullets. After 1967, the use of titanium plates in body armor gave further protection.

A typical modern nylon bulletproof vest is composed of 16-24 layers of heavyweave nylon fabric, quilt-stitched together. Ordinary bullets from submachine guns or pistols strike the outermost layers and deform into a mushroom shape that cannot penetrate the remaining layers, which dissipate its kinetic energy. Sixteen-layer vests can stop normal submachine gun or pistol bullets; 24-layer vests can stop magnum bullets. The wearer is generally bruised after such an impact, but receives no serious injury.
During the Vietnam war, pilots and crew of hovering helicopters required better protection against heavy ground fire. For this purpose, dual-hardness steel and ceramicl plastic composites were developed in the 1960s.

Dual-hardness steel gave ballistic protection $50 \%$ better than an equal weight of aluminum armor, as well as being able to absorb multiple hits better than shatterable ceramic armor. A tough crack-resisting rear face is metallurgically bonded to a very hard front face; the front face shatters the steel core of an incoming armor-piercing bullet while the ductile rear face absorbs the kinetic energy. The plates can be rolled to the thickness required to protect against a specific threat.

Ceramic composite armor is much lighter, consisting of hard ceramic plates reinforced with woven glass roving bonded with an elastic adhesive (or other plastic backing). The hardness of the ceramic slows the bullet abruptly by dissipating the projectile's energy as it shatters the ceramic. Ceramic tiles in a bulletproof vest must be replaced, though, because they shatter with every impact.

Aluminum oxide is the cheapest ceramic suitable for armor; boron carbide is the hardest such material, but is also the most expensive; silicon carbide provides a middle alternative, with hardness similar to boron carbide but less expensive. Tiles made from these ceramics are hot-pressed in graphite molds at temperatures higher than $2000^{\circ} \mathrm{C}$ and pressures greater than 2,000 psi.

Recent ceramic-metal composite materials, called "cermets," are five times more crack-resistant and shatter-resistant than conventional ceramics. The formation of cermets involves infiltrating moltenreactive metals into chemically treated boron carbide, boron, or boride powders or fibers. The resulting cermets have an unprecedented combination of hardness, toughness, and lightness. The properties of cermets are still being studied, and constitutive models of the material responses are under development. Researchers continue to refine the cermet-formation process to develop less expensive, commercially feasible production methods so cermets will attract more commercial exploitation. In the near future, cermet body armor could be the most effective form of bulletproof vest on the market. 


\section{Images of Materials}

Edited by David B. Williams, Alan R Pelton and Ronald

GRONSKY

This spectacularly illustrated book offers a dramatic introduction to the structural beauty of everyday materials and the space-age tech nologies used to probe their surface features and internal structures. 1992432 pp.; 410 illus., 78 color plates

505856-9 $\$ 75.00$

\section{Now available in paperback} High-Resolution Transmission Electron Microscopy and Associated Techniques EdITEd by Peter R Buseck, JoHN M. COWLEY AND LeRoY Eyring "A classic. . . authoritative, readable, and clearly shows the HRTEM can provide a wealth of information about thin solid specimens that is difficult, if not impossible, to obtain by any other analytical method." Journal of Solid State Chemistry 1989 (paper 1992) 672 pp.; 240 illus.

507262-6 paper $\$ 49.95$

504275.1 cloth $\$ 75.00$

\section{Basic Theory of \\ Surface States}

SYDNEY G. DAVISON AND

MARLA STESLICKA

This is a straightforward introduction to the theory of surface electronic states, accessible to all surface scientists familiar with quantum mechanics and solid-state physics. (Monographs on the Physics and Chemistry of Materials)

February $1992 \quad 240$ pp.; 83 illus. 851990.7 $\$ 65.00$

\section{Surface Electronic \\ Transport Phenomena in Semiconductors}

V.N. DOBROVOLSKY AND

V.G. LITOVCHENKO

This monograph provides a survey of the diverse experimental and theoretical results for electron and hole transport in surface and subsurface regions of semiconductors.

(Semiconductor Science and Technology No. 2)

1991240 pp.; 83 illus.

852034-4 \$79.00

Engineering in Process

\section{Metallurgy}

R.I.L. GUTHRIE

"....Could be expected to be a standard reference for many years." - Journal of Materials Processing Technology.

1989 (paper April 1992) 512 pp.;

220 illus.

$856367-1$ paper $\$ 49.95$

856222-5 cloth $\$ 115.00$

\section{Algebraic and Diagrammatic Methods in Many-Fermion}

Theory

Frank E. Harris, Hendrik J.

MONKHORST AND DAVID L.

FREEMAN

This advanced text presents modern theories of electronic structure and methods of incorporating electron correlation contributions.

1992416 pp.; 111 illus.

$506130-6 \quad \$ 75.00$

\section{The Mechanics of Crystals} and Textured Polycrystals

Willitam F. HosFord

This self-contained textbook presents a clear, concise review of the mechanics of crystals and polycrystals, and gives applications for solving problems related to the plastic deformation of metals.

(Oxford Engineering Science Series) July $1992 \quad 224$ pp.; 176 illus. 507744-X \$49.95

\section{Scanning Force Microscopy} With Applications to Electric, Magnetic, and Atomic Forces

DROR SARD

"Quite instructive as to the capabilities and limitations of the SFM, and should ignite the enthusiasm of those unconverted to high resolution microscopy." - Journal of Colloid and Interface Science. (Oxford Series in Optical and Imaging Sciences 2)

1991272 pp.; 79 illus.

506270-1 \$45.00

For more information or to order please write:

Oxford University Press 200 Madison Avenue, New York, NY 10016 Attn: Marketing Director for Science and Medical Books Prices and publication dates are subject to change
Variational Methods in

Mechanics

Toshio Mura AND

TATSUHito Koya

This helpful volume by a distin guished engineer and mathematician discusses variational methods in mechanics, the basis of much of the popular finite-element method. March 1992336 pp.; 73 illus. 506830-0 \$39.95

\section{The Role of Microscopy in Semiconductor Failure Analysis}

B.P. Richards AND P.K. FoORnER This concise handbook describes the applications of microscopy to semiconductor failure analysis. (Royal Microscopical Society Microscopy Handbooks 25)

August 1992104 pp.; 93 illus. $856432-5$ paper $\$ 24.95$

\section{Atomic and Molecular Beam Methods \\ Volume 2 \\ EDITED by Giacinto SCOLES}

This second volume of an advanced handbook on experimental molecula beam methods covers topics such as sub-doppler spectroscopy, photodissociation, molecular beam-masers, and others.

April $1992 \quad 816$ pp.; 278 illus. 504281-6 \$125.00

\section{Forthcoming}

\section{Elementary Dislocation} Theory

Julia R. WeERTMan AND

JOHANNNES WEERTMAN

May 1992240 pp.; 116 illus.

506900-5 paper $\$ 16.95$

\section{Chemical Change in Deforming Material}

M. BRIAN BAYLY

(Oxford Monographs on Geology and Geophysics)

September $1992 \quad 288$ pp.; 94 HTs 506764-9 \$55.00

\section{Transition Metal Oxides}

An Introduction to Their Electronic Structures and Properties

P.A. Cox

(International Series of Monographs on Chemistry 27)

August $1992 \quad 272$ pp.; 105 illus. $855570-9 \$ 75.00$ 


\section{Visit Academic Press at the SPRING MRS MEETING in Booth \#608}

\section{The Materials Science of Thin Films \\ Milton Ohring}

"Professor Milt Ohring has a long and unique perspective of thin film science from his dealings with academia and industry. This book represents his accumulated experiences of teaching andresearch. Thin film science is at the heart of many of our most advanced technologies. This book should prove invaluable not only to the university student but also to the professional who needs a broad overview of this important field." - J.M. POATE, AT\&T Bell Laboratories January 1992,704 pp. $\$ 69.95$

ISBN: 0-12-524990-X

\section{Compound Semiconductor Device Physics}

Sandip Tiwari

This book provides one of the most rigorous treatments of compound semiconductor device physics yet published. With its systematic and detailed discussion of low-dimensional physics, the use of statistical methods, and the use of one-, two-, and three-dimensional analytical and numerical analysis techniques, this book is ideal for both the researcher and the student. Although the emphasis of this text is on compound semiconductor devices, many of the principles discussed also will be useful to those interested in silicon devices. Each chapter ends with exercises that have been designed to reinforce concepts, to complement arguments or derivations, and to emphasize the nature of approximations by critically evaluating realistic conditions.

January $1992,828 \mathrm{pp} ., \$ 79.95$

ISBN: 0-12-691740-X

\section{The Spectroscopy \\ of Semiconductors}

edited by

David G. Seiler and Christopher L. Littler

A Volume in the SEMICONDUCTORS

AND SEMIMETALS Series

CONTENTS: Laser Spectroscopy of Semiconductors at Low Temperatures and High Magnetic Fields. Transient Spectroscopy by Ultrashort Laser Pulse Techniques. Piezospectroscopy of Semiconductors. Photoreflectance Spectroscopy of Microstructures. One- and Two-Photon Magneto-Optical Spectroscopy of $\mathrm{InSb}$ and $\mathrm{Hg}_{1-x} \mathrm{Cd}$ Te. Chapter References. Index.

May 1992, c. 416 pp., $\$ 99.50$ (tentative)

ISBN: 0-12-752136-4
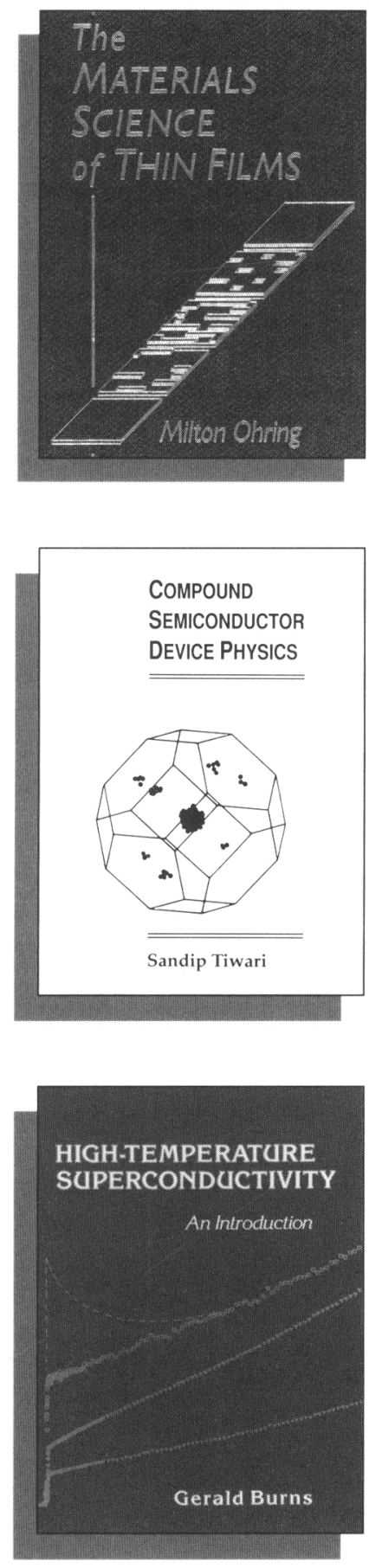

\section{Nanostructures and Mesoscopic Systems edited by \\ Wiley P. Kirk and Mark A. Reed}

The major topics addressed throughout the book include advances in nanostructure fabrication, mesoscopic systems, electron correlation and Coulomb blockade, low-dimensional tunneling, theory and modeling of nanostructures, ballistic transport and coherence, optical properties of nanostructures, and the challenge of new systems and issues.

March 1992,568 pp., \$69.95/ISBN: 0-12-409660-3

\section{Polymer Syntheses}

Volume I

SECOND EDITION

Stanley R. Sandler and Wolf Karo

A Volume in the ORGANIC CHEMISTRY Series

"I have been a user of this series for years and the authors have done a fine job on the second edition of Polymer Syntheses, Volume I."

-ELI M. PEARCE. Director. Polymer Research Institute Polytechnic University

January 1992,604 pp., $\$ 89.95$

ISBN: 0-12-618511-5

\section{High-Temperature Superconductivity}

\section{An Introduction}

Gerald Burns

Here is a concise, tutorial overview of the exciting new field of high-temperature superconductivity. This authoritative textbook focuses on topics, experimental results, and theoretical issues that are likely to have lasting value and are readily understandable to upperlevel undergraduates and others new to the field. Written primarily from an experimental point of view, the book reviews conventional superconductors and then presents the structure, normal state and superconducting properties, as well as applications of the new cuprate superconductors. An insightful analysis of critical currents in thin films and wires is included. The book will provide an excellent supplementary text for students taking their first solid state physics course. In addition, all those with a basic knowledge of solid state physics will find the book to be a useful introduction to the field.

Paperback: \$19.95/ISBN: 0-12-146090-8 January 1992, 224 pp.

Order from your local bookseller or directly from

19:1 1 a

Harcourt Brace Jovanovich, Publishers Book Marketing Department \#19042 1250 Sixth Avenue, San Diego, CA 92101 1-800-321-5068 FAX: 1-800-235-0256 Quote this reference number for free postage and handling on your prepaid order $=19042$ Prices subject to change without notice. 1992 by Academic Press, Inc. All Rights Reserved. SA/SS - 19042.

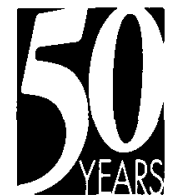




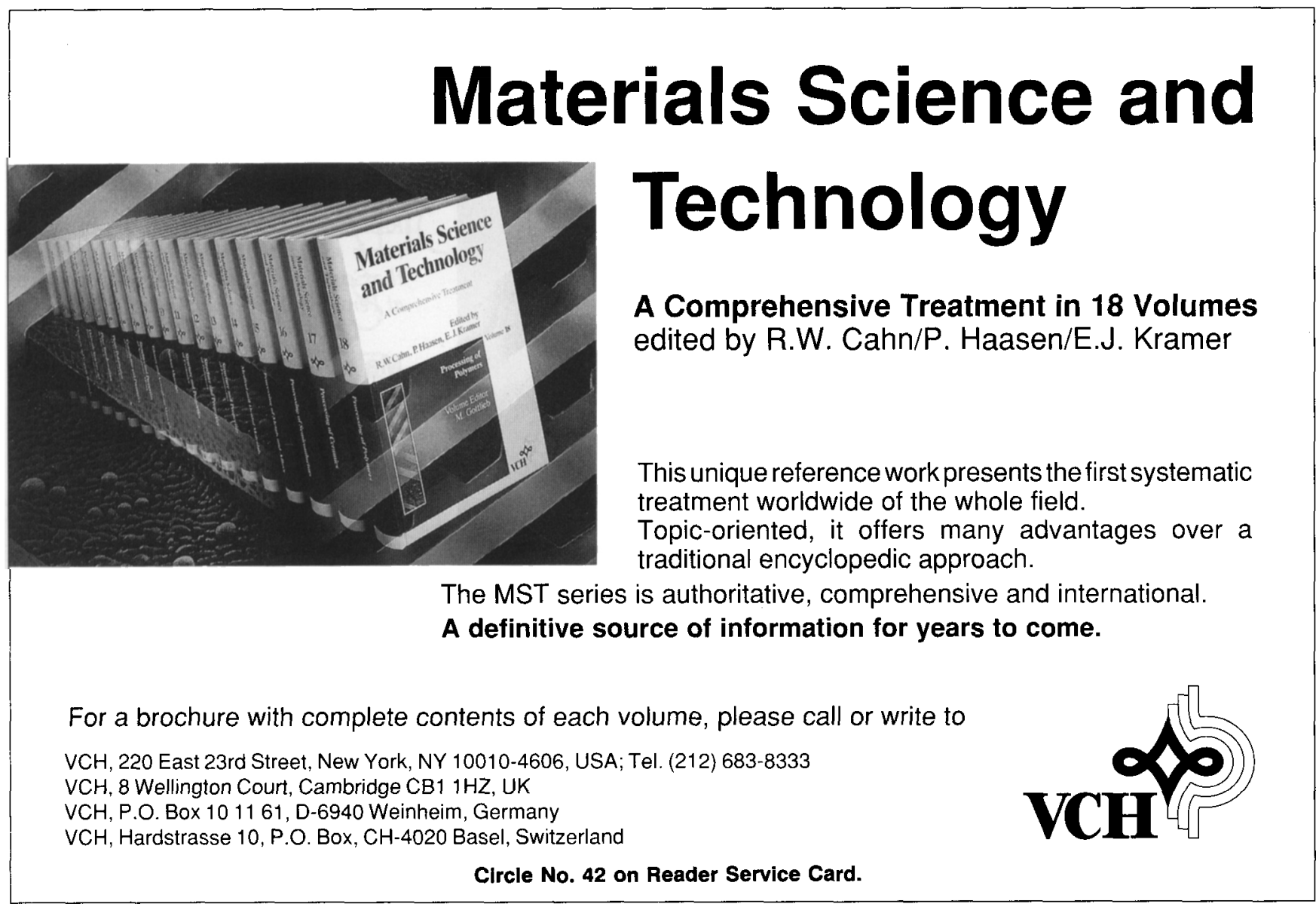

\section{BOOK REVIEWS}

\section{Fatigue of Materials}

\section{S. Suresh}

(Cambridge University Press, 1991,

520 pages).

ISBN: 0-521-36510-4

This comprehensive, up-to-date textbook includes a substantial treatment of fatigue in ceramics and polymers as well as in metallic materials. The emphasis is on the basic science of fatigue, although the short but useful final chapter includes design considerations and case studies. A basic knowledge of dislocations is assumed, but there is a brief introduction to continuum mechanics, a more substantial introduction to linear elastic fracture me chanics, and a helpful initial overview. Topics on which much attention has been focused in recent years are well covered, such as crack closure, threshold conditions, and the short crack problem. The extensive bibliography indicates that this is a very comprehensive and up-to-date treatment, especially from the fundamental and mechanistic points of view of the subject. Indeed, if used in a course on fatigue, some degree of selection and possibly reordering of the material would probably be required. However, this well-written book certainly will be a major reference in a field that continues to be of major importance in engineering and materials science.

Reviewer: G.W. Groves is a lecturer in the Department of Materials at the University of $O x$ ford.

\section{Sol-Gel Science: The Physics and Chemistry of Sol-Gel Processing \\ C. Jeffrey Brinker and George W.}

Scherer

(Academic Press, 1990, 881 pages).

ISBN: 0-12-134970-5

Over the past 15 years, sol-gel processing and synthesis of materials has grown from oddity status into a major interdisciplinary research and technological activity encompassing chemistry, physics, chemical engineering, and materials science. The rapid emergence of the field has resulted in the dispersion of its archival literature in a variety of conference proceedings and journals.

In this book, the authors have admirably accomplished their objective of presenting "a coherent account of the principles of solgel processing." As the first textbookquality publication describing the entire field of sol-gel science, the authors have had the opportunity (or onerous task) of presenting the fundamental principles underlying the unique characteristics of solgel systems.

The book is organized in the order of solgel processing, with the early chapters describing the chemical synthesis principles underlying hydrolysis and condensation. Subsequent chapters progress through gelation, aging of gels, deformation and flow, drying, structural evolution, surface chemistry, chemical modification, and sintering. The last three chapters discuss more specialized topics, such as comparisons of gelderived and conventionally produced ceramics, film formation, and applications. The phenomenology and fundamentals of each topic are thoroughly discussed and extensively referenced with more than 100 references following every chapter.

Each chapter is an excellent account of the specific topic, not surprising since the authors are pioneers in the sol-gel field and have contributed greatly to the development of its scientific foundations. A noteworthy feature is the critical analysis of topics and the authors' attempt to point out areas of controversy as well as those requiring more research.

At $\$ 140$, the book is somewhat expensive 